\title{
Clinical Application of Progesterone for the Prevention of Preterm Birth, 2016
}

\author{
William Goodnight, MD, MSCR ${ }^{1}$ \\ ${ }^{1}$ Maternal Fetal Medicine, University of North Carolina at Chapel Hill \\ School of Medicine, Chapel Hill, North Carolina \\ Am J Perinatol 2016;33:253-257.
}

\begin{abstract}
Address for correspondence William Goodnight, MD, MSCR, Maternal Fetal Medicine, University of North Carolina at Chapel Hill School of Medicine, 3010 Old Clinic Building, CB \# 7516, Chapel Hill, NC 275997516 (e-mail: william_goodnight@med.unc.edu).
\end{abstract}

\author{
Abstract \\ Keywords \\ - preterm birth \\ - recurrent preterm \\ birth \\ - progesterone \\ - vaginal progesterone \\ - cervical shortening
}

While the preterm neonate continues to benefit from improved perinatal care, the rate of preterm birth in the United States remains significant. An increasing body of scientific literature has demonstrated the benefits of maternal progesterone administration in reducing primary and recurrent preterm birth. Intramuscular hydroxyprogesterone caproate is indicated in singleton pregnancies in women with a prior spontaneous preterm birth, while vaginal progesterone demonstrates similar efficacy in prolonging pregnancy in women with asymptomatic cervical shortening in the midtrimester. Given these favorable benefits, the use of progesterone has been expanded to other clinical situations at risk for preterm birth with less rigorous scientific evidence. This review highlights the current evidence-based clinical applications of progesterone for prevention of preterm birth.
In the United States, $11.4 \%$ of pregnancies are delivered prior to 37 weeks' gestational age, with $1.5 \%$ of singleton births occurring prior to 33 weeks' gestational age. ${ }^{1}$ Despite improvements in the perinatal care of the premature neonate, prematurity continues to be a leading factor in perinatal morbidity; thus, interventions to reduce the rate of spontaneous preterm birth (РTB) can have significant impacts on perinatal morbidity. Progesterone administration in certain high-risk pregnancies has demonstrated ability to significantly prolong pregnancy and reduce the risk of PTB. Given the success of progesterone in specific clinical trials, there has been a widening of the indications for use of progesterone for prevention of prematurity to other clinical circumstances. As progesterone administration does not appear to reduce the rate of PTB in a general, low-risk population, ${ }^{2}$ identification of those who will benefit from progesterone is important. The aim of this review is to describe the available formulations of and the current evidence-based applications for the clinical use of progesterone for the prevention of spontaneous PTB.

received

November 19, 2015

accepted

November 24, 2015

published online

January 20, 2016

\section{Progesterone Formulations and Mechanisms of Action}

Multiple formulations of progesterone are currently commercially available and have been used for the purposes of prevention of PTB ( - Table 1). As of 2016, there is one FDAapproved progesterone, 17-hydroxyprogesterone caproate (17P) (Makena, AMAG Pharmaceuticals, Inc., Waltham, MA), approved for prematurity prevention. 17P is approved for prevention of spontaneous PTB in singleton pregnancies in patients with a prior spontaneous PTB. Micronized progesterone (MP) is administered via the vaginal route as compounded micronized vaginal suppositories (First Progesterone, CutisPharma Wilmington, MA), a vaginal gel (Crinone 8\%, Watson Pharma, Inc, Parsippany, NJ; Prochieve, Fleet Laboratories Ltd., Watford, United Kingdom), or vaginal administration of oral MP capsules (Prometrium, Solvay Pharmaceuticals, Inc, Marietta, GA). Oral progesterone formulations for PTB prevention have more limited data and inconsistent results. ${ }^{3,4}$

Copyright $\odot 2016$ by Thieme Medical Publishers, Inc., 333 Seventh Avenue, New York, NY 10001, USA. Tel: +1(212) 584-4662.
DOI http://dx.doi.org/ 10.1055/s-0035-1570378. ISSN 0735-1631. 
Table 1 Progesterone type, dosing, and clinical indications

\begin{tabular}{|l|l|l|l|}
\hline Progesterone & Dosing & How supplied & Clinical indications \\
\hline $\begin{array}{l}\text { 17-hydroxyprogesterone } \\
\text { caproate (Makena) }\end{array}$ & $250 \mathrm{mg} \mathrm{IM}$, weekly & $250 \mathrm{mg} / \mathrm{ml} ; 5 \mathrm{~mL}$ vial & $\begin{array}{l}\text { Singleton pregnancy in } \\
\text { woman with prior singleton } \\
\text { spontaneous preterm birth } \\
\text { between } 16 \text { and } 36 \text { weeks } \\
\text { gestation }\end{array}$ \\
\hline $\begin{array}{l}\text { Micronized progesterone } \\
\text { (First Progesterone) }\end{array}$ & $\begin{array}{l}200 \mathrm{mg} \text { via vaginal route } \\
\text { nightly }\end{array}$ & $\begin{array}{l}\text { Vaginal suppositories; } \\
\text { compounding kit; } 30 \text { each } \\
\text { per box }\end{array}$ & $\begin{array}{l}\text { Ultrasound identification of } \\
\text { short cervix prior to 24 } \\
\text { weeks' gestational age }\end{array}$ \\
\hline $\begin{array}{l}\text { Micronized progesterone } \\
\text { (Prometrium) }\end{array}$ & $\begin{array}{l}200 \mathrm{mg} \text { via vaginal route } \\
\text { nightly }\end{array}$ & $200 \mathrm{mg}$ oral capsule & $\begin{array}{l}\text { Ultrasound identification of } \\
\text { short cervix prior to 24 } \\
\text { weeks' gestational age }\end{array}$ \\
\hline $\begin{array}{l}\text { Progesterone gel: } \\
\text { (Crinone 8\% gel) }\end{array}$ & $\begin{array}{l}1.125 \mathrm{~g} / 90 \mathrm{mg} \text { via vaginal } \\
\text { route nightly }\end{array}$ & $1.125 \mathrm{~g}$ prefilled applicators & $\begin{array}{l}\text { Ultrasound identification of } \\
\text { short cervix prior to 24 } \\
\text { weeks' gestational age }\end{array}$ \\
\hline $\begin{array}{l}\text { Progesterone gel } \\
\text { (Prochieve 8\% gel) }\end{array}$ & $\begin{array}{l}1.4 \mathrm{gram} / 90 \mathrm{mg} \text { via vaginal } \\
\text { route nightly }\end{array}$ & $90 \mathrm{mg}$ prefilled applicators & $\begin{array}{l}\text { Ultrasound identification of } \\
\text { short cervix prior to 24 } \\
\text { weeks' gestational age }\end{array}$ \\
\hline
\end{tabular}

${ }^{\mathrm{a} F D A}$ Approved indication.

The mechanism of action of progesterone for prematurity prevention is poorly understood, but likely occurs through several pathways. Progesterone is a steroid hormone that affects target tissues, including the breast, ovaries, uterus, and central nervous system, via binding of progesterone receptors (PR-A and PR-B). Binding of progesterone to progesterone receptors results in a subsequent conformational change in the receptor leading to binding to target genes, ultimately affecting the regulation of gene transcription. ${ }^{5}$ The major purported end-organ effects of progesterone that influence PTB include an anti-inflammatory effect, which attenuates the proinflammatory state associated with initiation of labor, and a stabilization of progesterone effects on the myometrium resulting in maintenance of uterine quiescence. 6,7 While the clinical significance is unclear as it relates to prevention of PTB, plasma concentrations of progesterone are significantly greater with intramuscular administration, while vaginal administration results in greater uterine tissue concentrations, ${ }^{8}$ termed the uterine first-pass effect. ${ }^{5}$ Given the heterogeneity of etiologies that result in PTB, the route of administration may be relevant to the specific clinical circumstance, remaining an active area of investigation.

Progesterone has been shown to have a favorable maternal and fetal safety profile based on an extensive history of first trimester applications in fertility support as well as secondary analyses of 17P clinical trials (when used in the context of prematurity prevention). No increase in fetal anomalies or early childhood developmental delays has been associated with maternal progesterone use, ${ }^{9-11}$ resulting in a Pregnancy Category B US FDA classification for 17P. In addition, 17P is not associated with other adverse maternal obstetrical complications such as gestational diabetes. ${ }^{12}$ The most common side effects from 17P include incision site pain (35\%) and swelling (17\%), pruritus $(8 \%)$, and nausea $(6 \%){ }^{13}$

\section{Prior Spontaneous Preterm Birth}

The most well-studied indication for progesterone for PTB prevention is for the prevention of recurrent PTB. The Society for Maternal-Fetal Medicine and American College of Obstetricians proposed definitions of spontaneous PTB (-Fig. 1). In the first large randomized clinical trial, Meis et al demonstrated that in women with a current singleton pregnancy with a prior pregnancy complicated by PTB between $20^{0 / 7}$ and $36^{6 / 7}$ weeks' gestational age, administration of 17P starting at 16 to 20 weeks' gestational age resulted in a 30 to $40 \%$ reduction in the risk of recurrent PTB $<37$ weeks estimated gestational age (EGA) (relative risk [RR], 0.66 ; 95\% confidence interval $[\mathrm{CI}], 0.54-0.81$; rate of $\mathrm{PTB}$, 36.3 vs. $54.9 \%$; number needed to treat $5-6) .{ }^{14}$ In addition, $17 \mathrm{P}$ was associated with a reduction in perinatal morbidity including reductions in necrotizing enterocolitis, intraventricular hemorrhage, and need for supplemental oxygen. ${ }^{14}$ Subsequent trials have reinforced these findings. The optimal reduction in PTB appears with initiation of $17 \mathrm{P}$ prior to 21 weeks' EGA, but some benefit is noted with initiation of 17P by 27 weeks' EGA. ${ }^{15}$ Early cessation of 17 P has been associated with an increased risk of preterm delivery compared with continuation to 36 weeks.

Vaginal progesterone for the prevention of recurrent PTB with unknown cervical length has been less well evaluated with inconsistent results, ${ }^{16}$ and thus IM progesterone remains the first-line recommendation. Thus, in women with a current singleton pregnancy with a prior spontaneous PTB between $16^{0 / 7}$ and $36^{6 / 7}$ weeks, administration of $17 P$, $250 \mathrm{mg}$ intramuscularly (IM) weekly starting between 16 and $20^{6 / 7}$ weeks and continued until $36^{6 / 7}$ weeks, is recommended. ${ }^{7,17,18}$ Vaginal progesterone may be substituted if IM progesterone is not available. 


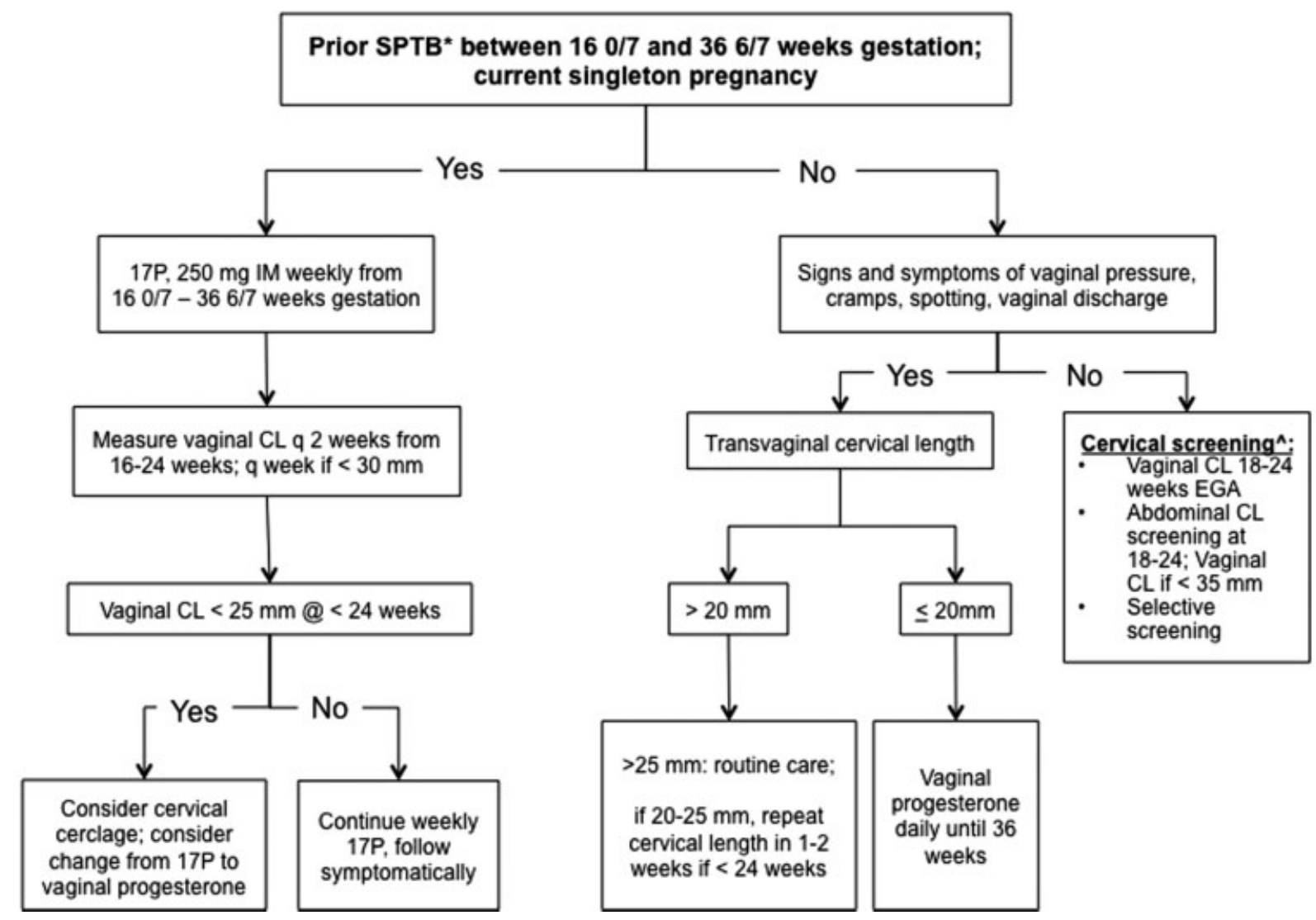

Fig. 1 Clinical use of progesterone in prevention of preterm birth. CL, cervical length; IM, intramuscular; SPTB, spontaneous preterm birth. ^ ${ }^{\top}$ The optimal protocol for cervical length screening is unproven and can be individualized to institution/practice based on population risk factors for preterm birth. There are no evidence-based guidelines for cervical length screening or progesterone treatment in multiple gestations. Spontaneous preterm birth includes the following: (1) singleton live birth between $16^{0 / 7}$ and $36^{6 / 7}$ weeks' gestation, following rupture of membranes or onset of labor; (2) stillbirth prior to 24 weeks presenting with labor, advanced cervical dilatation, or ruptured membranes; and ( 3 ) unclear circumstances of delivery (combination of spontaneous and indicated preterm birth, i.e., abruption).

\section{Asymptomatic Cervical Shortening}

Asymptomatic cervical shortening between 18 and 24 weeks of EGA is associated with an increased risk of PTB. ${ }^{19} \mathrm{~A}$ transvaginal ultrasound measured cervical length $\leq 25 \mathrm{~mm}$ in the midtrimester in singleton pregnancies is consistent with the 10th percentile for the population and is associated with a risk of PTB of 25 to $30 \%$, with a cervical length $<20 \mathrm{~mm}$ (3rd percentile) associated with a $50 \%$ risk of PTB, ${ }^{19}$ with similar associations with PTB in multiple gestation. Several randomized trials and a patient-level meta-analysis have demonstrated a reduction in PTB in women with asymptomatic cervical shortening (defined as transvaginal cervical length $\leq 20 \mathrm{~mm}$ between 16 and 24 weeks EGA) with the use of vaginal progesterone. In a meta-analysis of five high-quality trials with 775 patients, Romero et al demonstrated that the use of vaginal progesterone in the presence of midtrimester ultrasound cervical length $\leq 25 \mathrm{~mm}$ was associated with a $31 \%$ reduction in risk of PTB $<35$ weeks (RR, 0.69; 95\% CI, $0.55-0.88$ ) and similar reductions in PTB at $<33$ weeks (RR, $0.58 ; 95 \% \mathrm{CI}, 0.42-0.80$ ) and $<28$ weeks (RR, 0.50; 95\% CI, $0.30-0.81) .{ }^{12}$ Significant reductions in respiratory distress syndrome, birthweight $<1,500 \mathrm{~g}$, admission to neonatal intensive care unit, and composite neonatal morbidity and mortality were noted in those receiving vaginal progesterone. Population-based cervical length screening with the use of vaginal progesterone has been modeled as a cost-effective approach for the reduction of PTB in a general obstetric population, and is estimated to be superior to 17P use without screening or screening only women with a risk factor for PTB. ${ }^{20-22}$ The optimal timing and frequency of cervical length screening remains unproven, and universal cervical length screening has not been evaluated in large, randomized clinical trials, and thus individualization of institutional/regional screening protocols is suggested (-Fig. 1).

Clinical situations will arise where a patient with prior PTB currently undergoing treatment with 17P will develop cervical shortening. There are currently no randomized trials to address this specific circumstance. A meta-analysis by Berghella et al demonstrated a 30\% (RR, 0.70; 95\% CI, 0.55-0.89) reduction in PTB prior to 35 weeks of gestational age and a $36 \%$ reduction in composite neonatal morbidity and mortality with the addition of cervical cerclage in women with a prior PTB who develop cervical shortening in the midtrimester; thus, the addition of cerclage has been suggested in this setting. ${ }^{23}$ Importantly, the majority of women in this meta-analysis were not receiving 17P. A secondary analysis of a trial of cerclage for ultrasound 
identified short cervix did not demonstrate benefit of addition of cerclage in women currently receiving 17P who developed midtrimester ultrasound cervical length $<25$ $\mathrm{mm} .{ }^{24}$ In contrast, Conde-Agudelo et al conducted a systematic review and indirect comparison meta-analysis to compare cerclage and vaginal progesterone for asymptomatic short cervix in women with prior PTB. ${ }^{25}$ In this analysis of patients not currently receiving 17P, cerclage was not superior to vaginal progesterone in the prevention of PTB in women with a prior PTB and cervical length prior to 24 weeks $\leq 25 \mathrm{~mm}$, leading these authors to propose the use of vaginal progesterone over cerclage as a less invasive intervention. ${ }^{25}$ These authors also propose that in women with prior PTB currently receiving 17P who develop short cervix prior to 24 weeks' EGA, consideration of conversion from IM to vaginal progesterone may be appropriate; however, there is a paucity of data to this approach. Finally, Alfirevic et al evaluated a retrospective cohort of women with a prior PTB and ultrasound short cervix. In this analysis, treatments with pessary, vaginal progesterone, or cerclage were associated with similar rates of PTB. ${ }^{26}$

Thus, in women who are not currently taking 17P, daily vaginal progesterone from time of diagnosis until $36^{6 / 7}$ weeks is recommended for the identification of a transvaginal ultrasound cervical length $\leq 20 \mathrm{~mm}$ between 16 and $24^{0 / 7}$ weeks in an asymptomatic patient. ${ }^{18}$ Ultrasound screening protocols for cervical length between 16 and $24^{0 / 7}$ weeks should be individualized on an institutional/regional basis. In women currently receiving $17 \mathrm{P}$, progressive cervical shortening prior to 24 weeks' EGA, defined as transvaginal cervical length $\leq 25 \mathrm{~mm}$, may be treated with placement of cervical cerclage. Other management options in women with progressive cervical shortening with less rigorous study include addition or substitution of vaginal progesterone for IM progesterone or placement of vaginal pessary. Management of asymptomatic cervical shortening beyond 24 weeks is not well studied.

\section{Arrested Preterm Labor}

Several investigators have utilized 17P or vaginal progesterone for prevention of PTB following an episode of preterm labor. Rozenberg et al conducted an open-label randomized trial of 17P, $500 \mathrm{mg}$ twice weekly IM, in women following an episode of preterm labor defined as cervical length $\leq 25 \mathrm{~mm}$, contractions $>2$ per 10 -minute period, and cervix less than $3 \mathrm{~cm}$ dilated. ${ }^{27} 17 \mathrm{P}$ administration following acute tocolysis was not associated with a difference in time to delivery (61 vs. 63 days; $p=0.5$ ) or in PTB rates at 37, 34, or 32 weeks' EGA. ${ }^{27}$ A meta-analysis in 2015 of five randomized trials of $17 \mathrm{P}$ following an episode of symptomatic preterm labor demonstrated a 2.28 week ( $95 \% \mathrm{CI} 1.56-13.51$ ) later gestational age at delivery, 8.36 day $(95 \% \mathrm{CI}, 3.2-13.5)$ longer length of gestation, and higher mean birthweight $(224.3 \mathrm{~g}$; $95 \% \mathrm{CI}$, 70.81-377.74) in women who received 17P compared with controls. ${ }^{28}$ However, there was no difference in the rates of PTB $<37$ or $<34$ weeks with treatment of 17P following an episode of symptomatic preterm labor. ${ }^{28}$ A meta-analysis of vaginal progesterone following tocolysis for symptomatic preterm labor similarly demonstrated no difference in the rates of delivery $<37$ and $<34$ weeks' EGA, latency from randomization to delivery, or difference in respiratory distress syndrome, but again did demonstrate an association with increased birthweight (mean difference $203.32 \mathrm{~g}$; 95\% CI, 110.85-295.80; $p=0.032) .{ }^{29}$ Thus, based on the current scientific data, 17P and vaginal progesterone are currently not indicated for prevention of PTB following arrested symptomatic preterm labor in singleton or twin pregnancies. ${ }^{18}$

\section{Twin Pregnancy Prevention of Preterm Birth}

Given the high rate of spontaneous PTB in multiple gestations, effective measures to prevent PTB would be highly valuable. Randomized trials of 17P for the primary prevention of PTB in twin pregnancy with unknown cervical length have not demonstrated efficacy of 17P for the prevention of PTB or reduction in overall twin morbidity due to prematurity. ${ }^{30,31}$ Similarly, 17P has not demonstrated a reduction in PTB in twin pregnancies with ultrasound short cervix $<25 \mathrm{~mm}$. Vaginal progesterone in unselected twin pregnancies has also not demonstrated a reduction in the risk of PTB. ${ }^{32}$ Vaginal progesterone for midtrimester short cervix in twin pregnancies has not demonstrated lower rates of PTB compared with controls. ${ }^{33}$ In a meta-analysis by Romero et al, vaginal progesterone for cervical shortening $(\leq 25 \mathrm{~mm}$ in the midtrimester) did not reduce the rate of PTB prior to 33 weeks of gestation (30.4 vs. $44.8 \%$; RR, $0.70 ; 95 \%$ CI $0.34-1.44$ ), but was associated with a reduction in the composite neonatal morbidity (23.9 vs. $39.7 \%$; RR, 0.52 ; $95 \% \mathrm{Cl}, 0.29-0.93$ ) and demonstrated a reduction in the risk of PTB in twins $<37$ weeks in women with no prior PTB (RR, 0.52; $95 \% \mathrm{CI}, 0.29$ $0.93)^{12}$

Currently, based on the available scientific evidence, 17P and vaginal progesterone are not recommended for the primary prevention of PTB in unselected twin pregnancies, and 17P is not recommended for use in women with twin pregnancy with midtrimester cervical shortening. The influence of vaginal progesterone in prevention of PTB in the setting of a short cervical length in twin pregnancy $(<25 \mathrm{~mm})$ remains unclear, with some data suggesting improved neonatal outcomes. Ongoing large randomized clinical trials may provide further guidance in this clinical circumstance. ${ }^{34}$

\section{Conclusion}

Progesterone administration has been demonstrated to be a safe and effective intervention to date in the reduction of the risk of recurrent PTB as well as primary prevention of PTB in women with asymptomatic cervical shortening in the midtrimester. - Fig. 1 represents suggested guidelines for use of progesterone based on current scientific evidence and recommendations by Society for Maternal-Fetal Medicine and American College of Obstetricians and Gynecologists incorporating cervical length screening options. Identification of candidate patients and timely administration of progesterone will be expected to result in a reduction in the morbidity associated with PTB. 


\section{References}

1 Martin JA, Hamilton BE, Osterman MJ, Curtin SC, Matthews TJ. Births: final data for 2013. Natl Vital Stat Rep 2015;64(1):1-65

2 Hauth JC, Gilstrap LC III, Brekken AL, Hauth JM. The effect of 17 alpha-hydroxyprogesterone caproate on pregnancy outcome in an active-duty military population. Am J Obstet Gynecol 1983; 146(2):187-190

3 Rai P, Rajaram S, Goel N, Ayalur Gopalakrishnan R, Agarwal R, Mehta S. Oral micronized progesterone for prevention of preterm birth. Int J Gynaecol Obstet 2009;104(1):40-43

4 Glover MM, McKenna DS, Downing CM, Smith DB, Croom CS, Sonek JD. A randomized trial of micronized progesterone for the prevention of recurrent preterm birth. Am J Perinatol 2011;28(5):377-381

5 Ruan X, Mueck AO. Systemic progesterone therapy-oral, vaginal, injections and even transdermal? Maturitas 2014;79(3):248-255

6 Sfakianaki AK, Norwitz ER. Mechanisms of progesterone action in inhibiting prematurity. J Matern Fetal Neonatal Med 2006;19(12): 763-772

7 Society for Maternal-Fetal Medicine Publications Committe. Progesterone and preterm birth prevention: translating clinical trials data into clinical practice. Am J Obstet Gynecol 2012;206(5): 376-386

8 Miles RA, Paulson RJ, Lobo RA, Press MF, Dahmoush L, Sauer MV. Pharmacokinetics and endometrial tissue levels of progesterone after administration by intramuscular and vaginal routes: a comparative study. Fertil Steril 1994;62(3):485-490

9 Northen AT, Norman GS, Anderson K, et al; National Institute of Child Health and Human Development (NICHD) Maternal-Fetal Medicine Units (MFMU) Network. Follow-up of children exposed in utero to 17 alpha-hydroxyprogesterone caproate compared with placebo. Obstet Gynecol 2007;110(4):865-872

10 McNamara HC, Wood R, Chalmers J, et al. STOPPIT Baby Follow-up Study: the effect of prophylactic progesterone in twin pregnancy on childhood outcome. PLoS ONE 2015;10(4):e0122341

11 Dudás I, Gidai J, Czeizel AE. Population-based case-control teratogenic study of hydroxyprogesterone treatment during pregnancy. Congenit Anom (Kyoto) 2006;46(4):194-198

12 Romero R, Nicolaides K, Conde-Agudelo A, et al. Vaginal progesterone in women with an asymptomatic sonographic short cervix in the midtrimester decreases preterm delivery and neonatal morbidity: a systematic review and metaanalysis of individual patient data. Am J Obstet Gynecol 2012;206(2):124. e1-124.e19

13 Lumara Health I. Makena prescribing information. Available at: http://www.makena.com/pdf/makena_pi.pdf. Accessed November 5,2015

14 Meis PJ, Klebanoff M, Thom E, et al; National Institute of Child Health and Human Development Maternal-Fetal Medicine Units Network. Prevention of recurrent preterm delivery by 17 alphahydroxyprogesterone caproate. N Engl J Med 2003;348(24): 2379-2385

15 How HY, Barton JR, Istwan NB, Rhea DJ, Stanziano GJ. Prophylaxis with 17 alpha-hydroxyprogesterone caproate for prevention of recurrent preterm delivery: does gestational age at initiation of treatment matter? Am J Obstet Gynecol 2007;197(3):260.e1-260.e4

16 O'Brien JM, Adair CD, Lewis DF, et al. Progesterone vaginal gel for the reduction of recurrent preterm birth: primary results from a randomized, double-blind, placebo-controlled trial. Ultrasound Obstet Gynecol 2007;30(5):687-696

17 Iams JD. Clinical practice. Prevention of preterm parturition. N Engl J Med 2014;370(3):254-261

18 Society for Maternal-Fetal Medicine Publications Committee, with assistance of Vincenzo Berghella. Progesterone and preterm birth prevention: translating clinical trials data into clinical practice. Am J Obstet Gynecol 2012;206(5):376-386

19 Iams JD, Goldenberg RL, Meis PJ, et al; National Institute of Child Health and Human Development Maternal Fetal Medicine Unit
Network. The length of the cervix and the risk of spontaneous premature delivery. N Engl J Med 1996;334(9):567-572

20 Cahill AG, Odibo AO, Caughey AB, et al. Universal cervical length screening and treatment with vaginal progesterone to prevent preterm birth: a decision and economic analysis. Am J Obstet Gynecol 2010;202(6):548.e1-548.e8

21 Parry S, Simhan H, Elovitz M, Iams J. Universal maternal cervical length screening during the second trimester: pros and cons of a strategy to identify women at risk of spontaneous preterm delivery. Am J Obstet Gynecol 2012;207(2):101-106

22 Pizzi LT, Seligman NS, Baxter JK, Jutkowitz E, Berghella V. Cost and cost effectiveness of vaginal progesterone gel in reducing preterm birth: an economic analysis of the PREGNANT trial. Pharmacoeconomics 2014;32(5):467-478

23 Berghella V, Rafael TJ, Szychowski JM, Rust OA, Owen J. Cerclage for short cervix on ultrasonography in women with singleton gestations and previous preterm birth: a meta-analysis. Obstet Gynecol 2011;117(3):663-671

24 Szychowski JM, Berghella V, Owen J, et al; Vaginal Ultrasound Trial Consortium. Cerclage for the prevention of preterm birth in high risk women receiving intramuscular $17-\alpha$-hydroxyprogesterone caproate. J Matern Fetal Neonatal Med 2012;25(12):2686-2689

25 Conde-Agudelo A, Romero R, Nicolaides K, et al. Vaginal progesterone vs. cervical cerclage for the prevention of preterm birth in women with a sonographic short cervix, previous preterm birth, and singleton gestation: a systematic review and indirect comparison metaanalysis. Am J Obstet Gynecol 2013;208(1):42.e1-42.e18

26 Alfirevic Z, Owen J, Carreras Moratonas E, Sharp AN, Szychowski JM, Goya M. Vaginal progesterone, cerclage or cervical pessary for preventing preterm birth in asymptomatic singleton pregnant women with a history of preterm birth and a sonographic short cervix. Ultrasound Obstet Gynecol 2013;41(2):146-151

27 Rozenberg P, Chauveaud A, Deruelle P, et al; Groupe De Recherche En Obstétrique et Gynécologie. Prevention of preterm delivery after successful tocolysis in preterm labor by 17 alpha-hydroxyprogesterone caproate: a randomized controlled trial. Am J Obstet Gynecol 2012;206(3):206.e1-206.e9

28 Saccone G, Suhag A, Berghella V. 17-alpha-hydroxyprogesterone caproate for maintenance tocolysis: a systematic review and metaanalysis of randomized trials. Am J Obstet Gynecol 2015; 213(1):16-22

29 Eke AC, Chalaan T, Shukr G, Eleje GU, Okafor CI. A systematic review and meta-analysis of progestogen use for maintenance tocolysis after preterm labor in women with intact membranes. Int J Gynaecol Obstet 2015;132(1):11-16. doi:10.1016/j.ijgo.2015.06.058

30 Rouse DJ, Caritis SN, Peaceman AM, et al; National Institute of Child Health and Human Development Maternal-Fetal Medicine Units Network. A trial of 17 alpha-hydroxyprogesterone caproate to prevent prematurity in twins. N Engl J Med 2007; 357(5):454-461

31 Combs CA, Garite T, Maurel K, Das A, Porto M; Obstetrix Collaborative Research Network. 17-hydroxyprogesterone caproate for twin pregnancy: a double-blind, randomized clinical trial. Am J Obstet Gynecol 2011;204(3):221.e1-221.e8

32 Rode L, Klein K, Nicolaides KH, Krampl-Bettelheim E, Tabor A; PREDICT Group. Prevention of preterm delivery in twin gestations (PREDICT): a multicenter, randomized, placebo-controlled trial on the effect of vaginal micronized progesterone. Ultrasound Obstet Gynecol 2011;38:272-280

33 Klein K, Rode L, Nicolaides KH, Krampl-Bettelheim E, Tabor A; PREDICT Group. Vaginal micronized progesterone and risk of preterm delivery in high-risk twin pregnancies: secondary analysis of a placebo-controlled randomized trial and meta-analysis. Ultrasound Obstet Gynecol 2011;38(3):281-287

34 Reddy U. A trial of pessary and progesterone for preterm prevention in twin gestation with a short cervix (PROSPECT). Available at: ClinicalTrials.gov. Published 2015 